\title{
PTERIDÓFITAS DO ESTADO DE MATO GROSSO, BRASIL: VITTARIACEAE
}

\author{
Paulo G. Windisch ${ }^{1}$ \\ Fabiana R. Nonato ${ }^{2}$
}

Recebido em 30/03/1999. Aceito em 24/09/1999

\begin{abstract}
RESUMO - (Pteridófitas do Estado de Mato Grosso, Brasil: Vittariaceae). A família Vittariaceae está representada no Estado de Mato Grosso, Brasil, pelos gêneros Anetium, Antrophyum, Hecistopteris (com uma espécie cada) e Vittaria (com três espécies). Chaves de identificação para gêneros e espécies, breves descrições, ilustrações, bem como comentários sobre distribuição e habitats são apresentados.
\end{abstract}

Palavras-chave - Pteridophyta, Vittariaceae, samambaias, florística, Mato Grosso

\begin{abstract}
Pteridophytes of the State of Mato Grosso, Brazil: Vittariaceae). The family Vittariaceae is represented in the State of Mato Grosso, Brazil, by the genera Anetium, Antrophyum, Hecistopteris (a single species each) and Vittaria (with three species). Keys of the genera and species, brief descriptions, illustrations, as well as comments on the distribution and habitats are presented.
\end{abstract}

Key words - Pteridophyta, Vittariaceae, ferns, floristics, Mato Grosso

\section{Introdução}

A família Vittariaceae apresenta distribuição pantropical, estendendo-se até regiões temperadas, com algumas espécies na África do Sul, Japão, Sudeste dos Estados Unidos da América e na Argentina (Kramer 1990). Alguns autores como Copeland (1947) reconhecem nove gêneros, enquanto outros mais recentes, como Tryon \& Tryon (1982) e Kramer (1990), reconhecem seis gêneros. Destes gêneros, Hecistopteris J. Sm., Antrophyum Kaulf., Vittaria Sm. e Anetium (Kunze) Splitg. ocorrem na América Tropical, todos eles representados no Estado de Mato
Grosso. Na região paleotropical ainda ocorrem os gêneros Monogramma Schkuhr e Rheopteris Alston.

As vitariáceas constituem grupo com predominância de epífitas, podendo ocorrer também sobre rochas. As plantas apresentam frondes inteiras, pendentes, ou ainda diminutas e furcadas na parte apical. São anatomicamente incomuns em não apresentar esclerênquima e pela ocorrência de esclerídeos alongados (idioblastos espiculares) na epiderme da folha. Três dos gêneros podem ser considerados de ocorrência relativamente rara no Estado (Hecistopteris, Antrophyum e Anetium).

1 Universidade do Vale do Rio dos Sinos, UNISINOS, CCS, Avenida Unisinos, 950, CEP 93022-000, São Leopoldo, RS, Brasil

2 Curso de Pós-graduação em Botânica, Museu Nacional/Universidade Federal do Rio de Janeiro, Quinta da Boa Vista s/n, São Cristóvão, CEP 20940-040, Rio de Janeiro, RJ, Brasil 
Crane et al. (1995), utilizando técnicas de biologia molecular, verificaram a provável origem polifilética do gênero Vittaria a partir de análises de parcimônia utilizando características moleculares e morfológicas. Em revisão da circunscrição dos gêneros da família, Crane (1997) reconhece dez gêneros: Ananthacorus Underw. \& Maxon, Anetium Splitg., Antrophyum Kaulf., Haplopteris C. Presl, Hecistopteris J. Sm., Monogramma Schkuhr, Polytaenium Desv., Radiovittaria (Benedict) E. H. Crane, Scoliosorus T. Moore e Vittaria Sm. A aceitação desta proposta levaria a uma alteração na taxonomia de algumas espécies tratadas no presente trabalho, como indicado na discussão das mesmas.

\section{Material e métodos}

Este trabalho faz parte de uma série de publicações relativas às pteridófitas do Estado de Mato Grosso, desenvolvido com base no material coletado pelo primeiro autor e colaboradores em uma série de 24 viagens, a partir de 1974, amostrando as diversas regiões deste Estado, bem como no material mato-grossense encontrado nos principais herbários nacionais e estrangeiros. O sistema de classificação adotado segue basicamente o de Tryon \& Tryon (1982), sendo que eventuais diferenças em relação a outros sistemas são comentadas no texto. Sinônimos com mesma circunscrição de um dado táxon são apresentados quando encontrados nos trabalhos de Raddi (1819, $1825)$ e Fée $(1869,1873)$, ou ainda na Flora Brasiliensis, de Martius \& Urban, e trabalhos de Sehnem, na Flora Ilustrada Catarinense, com citações específicas apresentadas em cada caso. Foram incluídas referências adicionais dos táxons nas citadas obras, especialmente quando apresentam ilustrações. Maiores detalhes sobre a metodologia adotada e estruturação do texto podem ser encontrados nos trabalhos iniciais desta série (Windisch 1985, 1994). O material examinado é apresentado utilizando-se as siglas do Index Herbariorum (Holmgren et al. 1990), sendo SJRP a sigla do herbário do Instituto de Biociências, Letras e Ciências Exatas da Universidade Estadual Paulista, Campus de São José do Rio Preto.

\section{Resultados e discussão}

Vittariaceae (Presl) Ching, Sunyatsenia 5: 232. 1940. Vittarieae Presl, Tent. Pterid.: 164. 1836, como Vittariaceae.

Fase esporofítica representada por plantas epífitas, raramente terrestres. Caule subereto a curto-reptante, pequeno, ou longo-reptante e delgado, provido de escamas clatradas. Frondes monomorfas, vernação circinada, inteiras, ou (em Hecistopteris) furcadas, ou (em Rheopteris) pinadas. Nervuras livres ou anastomosantes, as aréolas sem vênulas incluídas. Esporângios agrupados em soros abaxiais, freqüentemente submersos, ou (em Anetium) a maioria dos esporângios em grupos dispersos sobre e entre as nervuras, sem indúsio; esporângios individuais geralmente com pedicelo bastante curto, com ânulo vertical, interrompido pelo pedicelo, estômio com quatro células; paráfises presentes ou ausentes; isosporados, esporos desprovidos de clorofila, monoletes ou triletes. Fase gametofítica epígea, clorofilada, talo alongado e irregularmente ramificado, às vezes com gemas.

Família composta por seis gêneros e cerca de 100 espécies, sendo quatro gêneros americanos, dos quais dois são pantropicais.

Bibliografia básica: Tryon \& Tryon (1982), Tryon \& Stolze (1989), Kramer (1990).

\section{Chave de identificação para os gêneros}

1. Frondes diminutas, em geral $1-4 \mathrm{~cm}$ longas, cuneadas a flabeladas, geralmente furcadas na parte apical 3. Hecistopteris

1. Frondes geralmente maiores que $4 \mathrm{~cm}$ e até $100 \mathrm{~cm}$ longas, lineares a elípticas, inteiras ...... 2

2. Esporângios em soros formando uma única linha paralela à cada margem das frondes ..

4. Vittaria

2. Esporângios em soros de disposição diversa, formando diversas linhas (ramificadas ou não) entre a costa central e as margens da fronde, ou ainda, espalhados sobre a superfície abaxial ou acompanhando a nervação anastomosante 3

3. Esporângios em soros definidos, sobre as nervuras, parcialmente imersos no tecido laminar 2. Antrophyum 
3. Esporângios sobre e entre as nervuras (por vezes mais concentrados sobre as nervuras), superficiais 1. Anetium

\section{Anetium}

Anetium (Kunze) Splitg., Tijdsch. Natuurl. Gesch. Physiol. 7: 395. 1840. Acrostichum sect. Anetium Kunze, Beibl. Flora 1839, I: 47.

Plantas epífitas (geralmente pendentes), raramente rupícolas. Caule longo-reptante, bastante delgado. Frondes $10-100 \mathrm{~cm}$ longas (usualmente $15-30 \mathrm{~cm}$ ), amplamente elípticas (por vezes estreitadas na base), inteiras, sésseis a subsésseis (frondes grandes com um estípite curto); lâmina glabra, cartácea a coriácea (podendo ser carnosa quando viva), margens planas ou um pouco revolutas ou ainda onduladas, costa distinta. Nervuras indistintas a obscuras, copiosamente anastomosantes, sem vênulas livres incluídas, as vênulas formando muitas séries de aréolas entre as margens e a costa, terminando em pontas livres próximo à margem. Esporângios isolados ou em pequenos agrupamentos espalhados sobre e entre as nervuras (por vezes mais concentrados sobre as nervuras), superficiais; paráfises ausentes; esporos triletes.

Gênero monotípico, neotropical, de ampla distribuição, que segundo Kramer (1990) talvez pudesse ser reunido com Antrophyum. Representado em Mato Grosso por:

Anetium citrifolium (L.) Splitg., Tijdschr. Natuurl. Gesch. Physiol. 7: 395. 1840. Fée, Crypt. Vasc. Brés. 1: 18. 1869. Sehnem, Fl. Il. Cat. I(Vitar.): 16, t. IV, f. 5. 1967.

Fig. 1-2

Acrostichum citrifolium L., Sp. pl. 1067. 1753. Tipo: Martinique, Plumier, Traité foug. Amér. t. 116. 1705.

Antrophyum citrifolium (L.) Fée, Mém. foug. 4: 51. 1852. Baker, in Martius \& Urban, Fl . Bras. I(2): 560. 1870.

Pteridanetium citrifolium (L.) Copel., Gen. fil.: 224. 1947.

Anetium citrifolium ocorre desde o México, Antilhas e América Central, até a Bolívia e sul do
Brasil (Santa Catarina). Representa gênero monotípico, acima descrito. Epífita nas bases de folhas de palmeiras, em mata, sendo de ocorrência rara.

Material examinado: BRASIL. Mato Groso:

Alta Floresta: ca. $50 \mathrm{~km}$ da cidade, assentamento rural de Carlinda, entre 6 a $10 \mathrm{~km}$ das margens do rio Teles Pires, Windisch 4763 (HB); Vila Bela da Santíssima Trindade, Serra Ricardo Franco, Windisch 708 (HB); idem, idem, Windisch $710(\mathrm{GH}$, $\mathrm{HB}, \mathrm{MG})$; idem, idem, Windisch 1270 (HB); idem, idem, Windisch 1694 (HB).

\section{Antrophyum}

Antrophyum Kaulf., Enum. fil.: 197. 1824.

Plantas epífitas, por vezes rupícolas. Caule curto-reptante a ascendente. Frondes $3-50 \mathrm{~cm}$ longas, inteiras, lineares a suborbiculares, sésseis a subsésseis; lâmina glabra, papirácea a coriácea, margens planas ou um pouco revolutas ou ainda onduladas, costa distinta ou obscura. Nervuras anastomosantes, sem vênulas livres incluídas, as vênulas formando muitas séries de aréolas entre as margens e costa; ou livres. Esporângios em soros definidos, sobre as nervuras, parcialmente imersos no tecido laminar, superficiais ou em sulcos entre a costa e a margem; paráfises presentes e numerosas (subgênero Antrophyum) ou ausentes (subgênero Polytaenium); esporos monoletes ou triletes.

Gênero pantropical com mais de 40 espécies, com cerca de 18 na América. Representado em Mato Grosso por uma única espécie, a saber:

Antrophyum cajenense (Desv.) Spreng., Syst. veg. 4: 67. 1827.

Fig. 3

Hemionitis cajenensis Desv., Ges. Naturf. Freunde Berlin Mag. Neuesten Entdeck. Gesammten Naturk. 5: 311. 1811. Tipo: Guiana Francesa, Herb. Desv. (P).

Polytaenium cajenense (Desv.) Benedict, Bull. Torrey Bot. Club 38: 169. 1911.

Plantas epífitas. Caule curto-reptante. Frondes ca. $10-35 \mathrm{~cm}$ longas, inteiras, estípite geralmente castanho escuro abaxialmente, fortemente alado; lâmina oblanceolada, papirácea a coriácea. Esporângios formando muitas linhas 

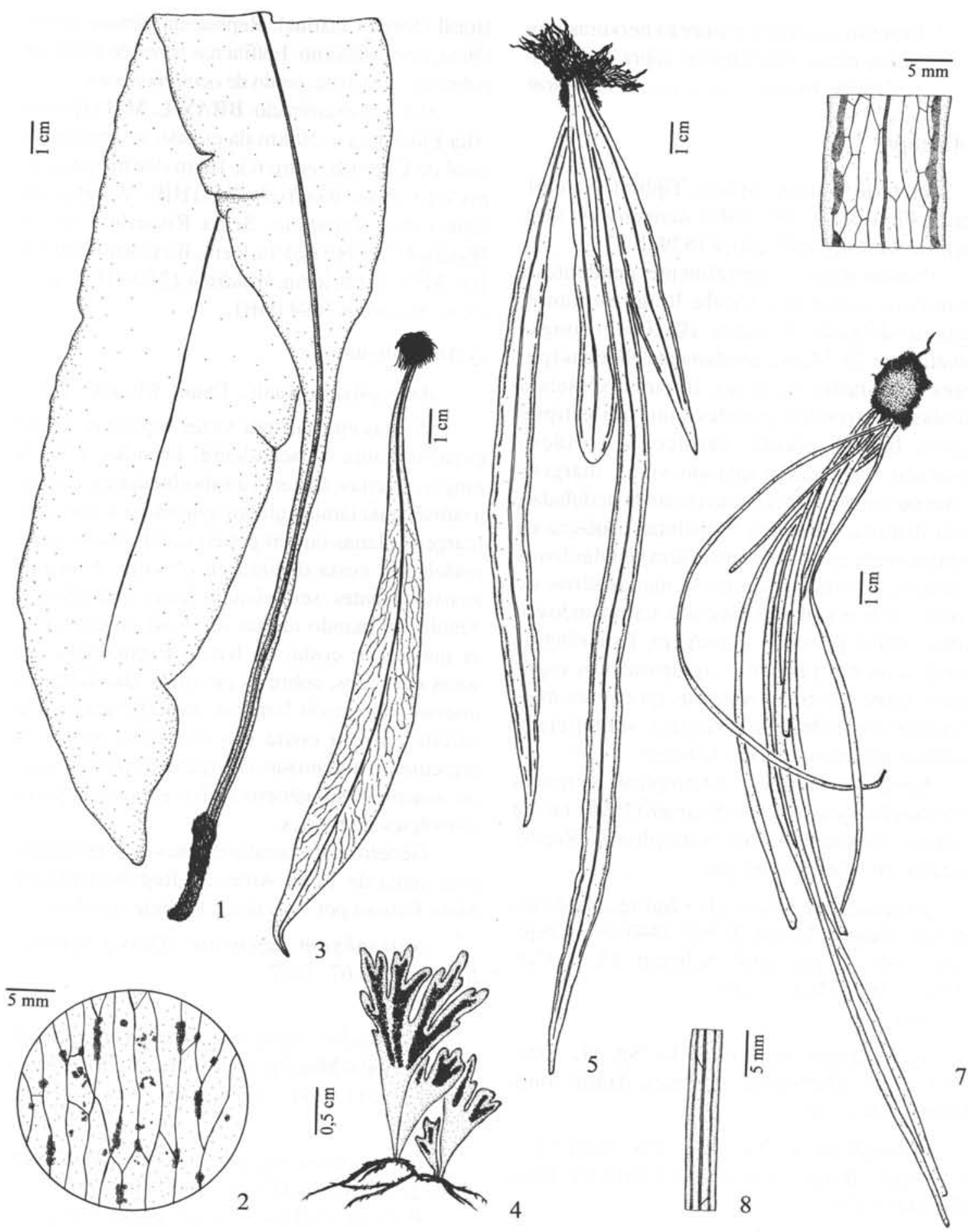

Figuras 1-8. 1-2. Anetium citrifolium. 1. aspecto geral do esporófito; 2. detalhe da disposição dos soros sobre a lâmina (Windisch 1694, HB). 3. Antrophyum cajenense, aspecto geral do esporófito (Pivetta 293, HB). 4. Hecistopteris pumila, idem (Windisch 4738, HB). 5-6. Vittaria costata. 5. aspecto geral do esporófito; 6. detalhe da nervação com várias séries de aréolas (Windisch 1713, HB).78. Vittaria lineata. 7. aspecto geral do esporófito; 8. detalhe da nervação com apenas uma série de aréolas (Windisch 1541, HB). 
de soros, seguindo quase todas as nervuras; esporos triletes.

Ocorre desde o sul do México até Panamá, Grandes Antilhas; na América do Sul, desde as Guianas até Colômbia, sul até Bolívia e Brasil. Espécie muito similar a Antrophyum brasilianum Desv., sendo esta considerada por alguns autores como variação de A. cajenense. Epífita sobre tronco, ocorrendo em mata.

Caso aceito o sistema proposto por Crane (1997), o binômio Polytaenium cajenense teria que ser aplicado a esta espécie.

Material examinado: BRASIL. Mato Grosso: Cotriguaçú, Pivetta 293 (HB); Itaituba, estrada Santarém - Cuiabá, divisa Pará/Mato Grosso, M. N. Silva 366 (K).

\section{Hecistopteris}

Hecistopteris J. Sm., Lond. J. Bot. 1: 193. 1842.

Plantas epífitas, raro rupícolas. Caule curtoreptante. Frondes 1 a $4 \mathrm{~cm}$ longas, cespitosas, em geral alargadas (cuneadas a flabeladas), geralmente furcadas na parte apical, sésseis a com estípite curto; lâmina glabra, papirácea, margens planas, sem costa distinta. Nervuras livres. Esporângios longo-pedicelados, formando soros lineares, superficiais, sobre a parte distal das nervuras, mas não chegando ao ápice das mesmas; paráfises presentes e numerosas; esporos triletes.

Gênero até recentemente tido como monotípico, contudo, populações de espécies locais diferenciadas são reconhecidas no Equador $(H$. pinnatifida R. C. Moran \& B. Øllgaard) e na Guiana (H. kaieteurensis Kelloff \& G. McKee). Sua ocorrência estende-se do México, Antilhas e América Central, até a Bolívia e sul do Brasil (Santa Catarina). Representado em Mato Grosso pela espécie de ampla distribuição, à qual se aplica a descrição genérica apresentada:

Hecistopteris pumila (Spreng.) J. Sm., London J. Bot. 1: 193. 1842. Fée, Crypt. Vasc. Brés. 1:58. 1869. Sehnem, Fl. Il. Cat. I (Vitar.): 11, t. IV, f. 4. 1967.

Fig. 4

Gymnogramma pumila Spreng., Tent. suppl. Syst. veg.: 31 . 1828. Tipo: Suriname, Weigelt $s / n$
(B, P). Baker, in Martius \& Urban, Fl. Bras. I(2): 551. 1870.

Esta espécie de pequeno porte é referida por Tryon \& Stolze (1989) como rara nas florestas tropicais, provavelmente pela dificuldade de encontrar os seus indivíduos na natureza. Epífita sobre tronco, ocorrendo em mata.

Material examinado: BRASIL. Mato Grosso: Alta Floresta, $12 \mathrm{~km} \mathrm{~S}$ da cidade, ao longo da "Primeira Sul", Windisch 4738 (HB, SJRP); Juína: Chácara do Seminário, Pivetta 1467 (HB).

\section{Vittaria}

Vittaria Sm., Mém. Acad. Roy. Sci. (Turin) 5: 413.1793 .

Plantas epífitas (geralmente pendentes), raramente rupícolas, muito raramente terrestres. Caule subereto a curto-reptante. Frondes até $100 \mathrm{~cm}$ longas, inteiras, lineares a linear-elípticas ou linear-lanceoladas, sésseis ou com estípite curto; lâmina glabra, cartácea a subcoriácea, margens planas a revolutas, costa distinta ou obscura. Nervuras anastomosantes, formando uma a cinco séries de aréolas estreitas de cada lado da costa, sem vênulas livres incluídas. Esporângios longo-pedicelados, em fenda rasa ou profunda, formando soros em uma única linha paralela à cada margem das frondes (às vezes quase marginal); paráfises presentes e numerosas; esporos monoletes ou triletes.

Gênero ocorrente nas regiões tropical e subtropicais do globo, com cerca de 60-70 espécies, a maioria concentrada na região Paleotropical. Na América ocorrem cerca de dez espécies (Tryon \& Stolze 1989), das quais três estão representadas no Estado de Mato Grosso, podendo ser reconhecidas através dos caracteres apresentados na chave a seguir:

Chave para a identificação de espécies de

\section{Vittaria}

1. Lâmina linear-lanceolada, ca. 0,8-1,2cm larg., nervação com duas ou mais séries de aréolas entre a costa e a margem 1. V. costata

1. Lâmina linear, ca. $0,1-0,4 \mathrm{~cm}$ larg. , nervação com uma única série de aréolas entre a costa e a margem 
2. Paráfises delgadas, com a célula apical não ou apenas levemente alargada; esporos reniformes, monoletes 3. V. lineata

2. Paráfises firmes, com a célula apical alargada; esporos tetraédrico-globosos, triletes

\section{V. graminifolia}

1. Vittaria costata Kunze, Linnaea 9: 77. 1834; Anal. Pterid. 29, t. 18, f. 2. 1837. Tipo: Peru, Huallaga, Tocache, Poeppig (W).

Fig. 5-6

Pteris angustifolia Sw., Prodr:: 129. 1788. Tipo: Jamaica e Hispaniola (Fl. Ind. Occid. 3: 1599. 1806).

Vittaria angustifolia (Sw.) Baker, in Martius \& Urban, Fl. Bras. 1(2): 544. 1870, non V. angustifolia Blume, Enum. pl. Javae 199. 1828.

Ananthacorus angustifolius (Sw.) Underw. \& Maxon, Contr. U. S. Natl. Herb. 10: 487. 1908.

Plantas epífitas. Caule dorsiventral. Frondes $10-55 \mathrm{~cm}$ longas, ca. 0,8-1,2cm largas, pendentes; estípite praticamente ausente; lâmina linearlanceolada, subcoriácea, costa evidente. Nervuras anastomosantes, formando duas ou mais séries de aréolas entre a costa e a margem. Esporângios quase superficiais, em duas linhas distanciadas das margens; paráfises castanhas, estreitamente clavadas; esporos monoletes.

Ocorre desde o México, Antilhas e América Central, até Bolívia e sul do Brasil. Espécie rupícola e também epífita sobre tronco, ocorrendo em mata.

Espécie caracterizada pela nervação com duas ou mais séries de aréolas em cada lado da costa; todas as outras espécies deste gênero têm uma única série de aréolas.

Caso aceito o sistema proposto por Crane (1997), o binômio Ananthacorus angustifolius teria que ser aplicado a esta espécie.

Material examinado: BRASIL. Mato Grosso: Cotriguaçú, Pivetta 274 (HB); idem, Pivetta 1477 (HB); Vila Bela da Santíssima Trindade, Serra Ricardo Franco, Windisch 678 (HB); idem, Windisch 768 (HB); idem, Windisch 1713 (HB). Sem município definido, "Mato do Curupira et Serra do Itapirapuan”, Lindman A3453 (S, US); Mato Grosso, Smith 102 (R).

2. Vittaria graminifolia Kaulf., Enum. fil.: 192. 1824. Tipo: Brasil, holótipo destruído (LZ); provável isótipo, Herb. Greville (E).
Vittaria lineata var. graminifolia (Kaulf.) Ros. Hedwigia 46: 149. 1824. Sehnem, Fl. Il. Cat. I(Vitar.): 10, t. IV, f. 3. 1967.

Vittaria filifolia Fée, Mém. foug. 3: 20, t. 3, f. 6. 1852 .

Plantas epífitas, raramente rupícolas. Caule dorsiventral. Frondes $8-50 \mathrm{~cm}$ longas, ca. 0,1-0,2cm largas, pendentes; estípite mais claro que a lâmina e um pouco achatado; lâmina linear, cartácea, costa evidente. Nervuras anastomosantes, formando uma única série de aréolas entre a costa e a margem. Esporângios em sulcos pouco profundos próximos às margens; paráfises firmes, castanho-avermelhadas a castanho-avermelhadas escuras, a célula apical alargada; esporos tetraédrico-globosos, triletes.

Ocorre desde o sul do México, Antilhas, até Bolívia e sul do Brasil. Epífita sobre tronco, às vezes rupícola, ocorrendo em matas.

No aspecto geral Vittaria graminifolia se assemelha muito a Vittaria lineata, ilustrada no presente trabalho, diferenciando-se pelos caracteres apresentados na chave de identificação.

Material examinado: BRASIL. Mato Grosso: sem município definido, Smith 53 (R).

3. Vittaria lineata (L.) Sm., Mém. Acad. Roy. Sci. (Turin) 5: 421. 1793. Fée, Crypt. Vasc. Brés. 1: 27. 1869. Fée, Crypt. Vasc. Brés. Suppl. 2: 19. 1873. Sehnem, Fl. Il. Cat. I(Vitar.): 8, t. III e IV, f. 2. 1967.

Fig. 7-8

Pteris lineata L., Sp. pl. 2: 1073. 1753. Tipo: Santo Domingo, Plumier, Traité foug. Amér. t. 143. 1705.

Plantas epífitas. Caule dorsiventral. Frondes 10-100 cm longas, ca. 0,2-0,3 cm largas, pendentes; estípite mais claro que a lâmina e um pouco achatado; lâmina linear, cartácea a subcoriácea, costa evidente. Nervuras anastomosantes, formando uma única série de aréolas entre a costa e a margem. Esporângios em profundos sulcos um pouco distanciados das margens; paráfises castanhas a castanho-avermelhadas com célula apical não ou muito pouco expandida; esporos monoletes.

Ocorre nos Estados Unidos da América, Antilhas, América Central, até Paraguai e sul do 
Brasil. Epífita nas bases de folhas de palmeiras, em mata.

Espécie bastante próxima de Vittaria graminifolia Kaulf., que contudo apresenta esporos triletes. Caracterizada por apresentar soros em sulcos profundos com aletas em cada lado, paráfises com a célula apical não ou apenas levemente alargada e esporos monoletes.

Material examinado: BRASIL. Mato Grosso: Cáceres, Hoehne 4172 (R); Jauru, Hoehne 903, 904 (R); distrito de Taquaruçú, rio Jauru, Windisch \& Pires 6724 (SJRP); Juína, Chácara da Cooperativa, Pivetta 1505 (HB); Ribeirão da Cascalheira, "W of the rio SuiaMissú”, Harley \& Souza 11.169 (K, US); São Manoel, Hoehne 5261 (R); Vila Bela da Santíssima Trindade, Serra Ricardo Franco, Windisch 1290 (HB); idem, idem, Windisch 1484 (HB); idem, idem, Windisch 1541 (HB); sem município definido, "Cupim, prope Palmeiras", Lindman A2527 (S, US); Palmeiras, Cupim, Lindman A2527a (S); "Poaia", Lindman $s / n$ (S); Mato Grosso, Diogo 64 (R); idem, Hoehne 5379 (R).

\section{Agradecimentos}

Os autores registram seu reconhecimento aos curadores dos herbários citados, pela atenção e paciente cooperação, bem como a todos aqueles que recolheram espécimes em que este trabalho se baseia. Merece especial destaque a colaboração de Carlos Marinoni, Márcio R. Pietrobrom-Silva e Walter de Oliveira durante a realização de trabalhos de campo. O Dr. Jefferson Prado e relatores anônimos contribuíram com oportunas sugestões. As ilustrações foram preparadas por Claudia R. Siqueira. A maior parte deste trabalho foi desenvolvida na Universidade Estadual Paulista, UNESP, campos de São José do Rio
Preto; ao Conselho Nacional de Desenvolvimento Científico e Tecnológico - CNPq, ela concessão de bolsa de Produtividade em Pesquisa ao primeiro Autor, e de Mestrado, à segunda Autora.

\section{Referências Bibliográficas}

Copeland, E. B. 1947. Genera filicum, the genera of ferns. Chronica Botanica, Waltham, Massachussetts.

Crane, E. H.; Farrar, D. R. \& Wendel, J. F. 1995. Phylogeny of the Vittariaceae: convergent simplification leads to a polyphyletic Vittaria. American Fern Journal 85(4): 283-305.

Crane, E. H. 1997. A Revised Circumscription of the Genera of the Fern Family Vittariaceae. Systematic Botany 22(3): 509-517.

Fée, A. L. A. 1869. Cryptogames vasculaires du Brésil. Veuve Berger-Levrault \& Fils., Strasbourg.

Feé, A. L. A. 1873. Cryptogames vasculaires du Brésil. II partie: Supplément et révision. Berger-Levrault \& Cie., Nancy.

Holmgren, P. K.; Holmgren, N. H. \& Barnet, L. 1990. Index Herbariorum part I: The herbaria of the world. $8^{a}$ ed. International Association for Plant Taxonomy, New York Botanical Garden, New York.

Kramer, K. U. 1990. Vittariaceae. Pp. 272-277. In: K. Kubitzki (Ed.), The families and genera of vascular plants. Vol. I. Pteridophytes and Gymnosperms. K. U. Kramer. \& P. S. Green (Ed. vol.). Springer Verlag, Berlin.

Raddi, J. 1819. Synopsis filicum brasiliensium... Opuscoli Scientifici. Bologna 3: 279-297.

Raddi, J. 1825. Plantarum brasiliensium nova genera et species novae, vel minus cognitae. Typographia Aloisii Pezzati, Florentiae.

Tryon, R. M. \& Stolze, R. G. 1989. Pteridophyta of Peru: part II. 13. Pteridaceae - 15. Dennstaedtiaceae. Fieldiana: Botany 22: 83-93.

Tryon, R. M. \& Tryon, A. F. 1982. Ferns and allied plants, with special reference to Tropical America. Springer Verlag, New York.

Windisch, P. G. 1985. Pteridófitas do Estado de Mato Grosso - Considerações gerais e chave para as famílias. Bradea IV(28): 180-187.

Windisch, P. G. 1994. Pteridófitas do Estado de Mato Grosso: Gleicheniaceae. Bradea VI(37): 204-311. 